\title{
PROFUNDIDADE DO LENÇOL FREÁTICO NO CULTIVO DE CANOLA
}

\author{
E. DE ROSSI ${ }^{1 *}$, C. A. LINDINO', R. F. SANTOS ${ }^{1}$, P. A. CREMONEZ ${ }^{1}$, K. G. SANTOS ${ }^{2}$, J. ANTONELLI ${ }^{1}$ e W. C. \\ NADALETTI' \\ 'Universidade Estadual do Oeste do Paraná \\ ${ }^{2}$ Universidade Federal do Paraná \\ eduderossi@gmail.com*
}

Artigo submetido em dezembro/2013 e aceito em outubro/2015

DOI: 10.15628/holos.2015.1861

\section{RESUMO}

Desde os primórdios do surgimento da agricultura os níveis do lençol freático são parte importante na produção de alimentos, já nos dias atuais, esta produção se abrange também para setores como o energético e ambiental. A canola (Brassica napus L.), no Brasil, teve nos últimos anos um aumento expressivo de produção devido ao grande interesse, principalmente alimentar e energético. Um fator que poderia facilitar o seu plantio é o conhecimento de sua necessidade hídrica, em relação à profundidade do lençol freático. Neste sentido, objetivou-se avaliar o efeito da variação de níveis de lençol freático no crescimento inicial da canola. O trabalho foi realizado em lisímetros com diâmetro de 20 $\mathrm{cm}$ em casa de vegetação da UNIOESTE, campus Cascavel. O delineamento experimental foi inteiramente casualizado com seis tratamentos e seis repetições de profundidade do lençol freático: 0,$1 ; 0,2 ; 0,3 ; 0,4 ; 0,5$ e $0,6 \mathrm{~m}$. Avaliou-se a altura de planta, número de folhas, área foliar, comprimento radicular, massa fresca e seca, parte aérea e radicular. O cultivo da canola em locais onde o lençol freático, de água, é menor que $20 \mathrm{~cm}$ de profundidade tende a gerar dificuldades para seu desenvolvimento, e em profundidades de 40 á 60 são mais indicadas.

PALAVRAS-CHAVE: Brassica napus L., manejo da irrigação, hídrica.

\section{DEPTH OF WATER TABLE IN THE CULTURE OF CANOLA}

\begin{abstract}
Since the beginning of the rise of agriculture groundwater levels are an important part in the production of food, already today, this production is also to cover sectors such as energy and the environment. The canola in Brazil in recent years has had a significant increase in production due to the great interest, especially food and energy. One factor that could facilitate their planting is the knowledge of its water requirement in relation to the water table depth. Therefore, aimed up to evaluate the effect of different levels of groundwater in the initial growth of canola. The work was carried out in
\end{abstract}

lysimeterswith a diameter of $20 \mathrm{~cm}$ in a greenhouse UNIOESTE campus Rattlesnake. The experimental design was completely randomized with six treatments and six replications of the water table depth: $0.1,0.2,0.3,0.4$, 0.5 and $0.6 \mathrm{~m}$. We evaluated the plant height, leaf number, leaf area, root length, fresh and dry, root and shoot. The cultivation of canola in places where the water table, water, is less than $20 \mathrm{~cm}$ depth tends to cause difficulties for their development, and at depths of 40 to 60 are more suitable.

KEYWORDS: Brassica napus L., irrigation management, water. 


\section{INTRODUÇÃO}

Enquanto no Brasil e nos Estados Unidos a produção de biodiesel se concentra principalmente na utilização de óleo de soja para produção dos ésteres alquílicos, a Europa tem seu maior percentual de biodiesel produzido a partir do óleo de canola. No Brasil, a soja entra como principal insumo em mais de 70\% nas usinas produtoras de biodiesel (TAPANES et al., 2013).

No Brasil existe uma variada gama de possibilidades de utilização de matéria-prima para a produção de biodiesel, principalmente pelo clima favorável, e a disponibilidade de terras agricultáveis e para expansão agrícola, além da disponibilidade de mão-de-obra. O Governo brasileiro pretende evitar, com o biodiesel, a nova ocorrência de concentração em uma cultura ou fonte específica, para a produção de um biocombustível, como acontecido na monocultura da cana-de-açúcar para produzir etanol (RODRIGUES, 2006).

Por isto, faz-se necessário, pesquisas com relação às condições para melhores produtividades de oleaginosas com intuito de produzir biodiesel. E como a canola já é uma cultura bem aproveitada para esta destinação na Europa, com o passar do tempo pode a ser muito apreciada para a produção de biodiesel também no Brasil.

Sendo uma cultura que contribui pela redução da ocorrência de doenças nas culturas subsequentes por ser uma crucífera e não hospedar a maioria das pragas e doenças que ocorrem em espécies gramíneas e leguminosas (TOMM et al., 2008).

Dogan et al. (2011) relatam que houve uma maior eficiência de uso da água obtida através diferentes tratamentos por irrigação, sistema de aspersão, indicando uma forte relação positiva entre o rendimento das culturas e irrigação. Faraji et al. (2009) relatam que a irrigação suplementar é prática eficiente para mitigar o estresse hídrico aumentando consequentemente a massa seca da parte aérea e produtividade de grãos. Existem poucas informações disponíveis com relação às necessidades hídricas no cultivo da canola e sob condições de irrigação, especialmente no que diz respeito a aumentar o seu crescimento vegetativo (BAÑUELOS et al., 2002).

Neste sentido, o Lençol freático pode ser um fator preponderante para o cultivo da canola em algumas áreas especificas. Segundo Cruciani $^{1}$ (1987), a recarga do lençol freático pode se dar através de percolação, advinda da precipitação e irrigação, ocorrendo através da zona insaturada do solo; infiltração advinda de canais e cursos d'água naturais, cujo nível é superior ao nível freático; fluxo ascendente advindo das camadas inferiores do aquífero devido a uma pressão artesiana; fluxo de entrada lateral advindo de uma área adjacente onde o nível freático é mais elevado do que na área em questão (apud NIERO, 2011).

Com intuito de controlar o nível do lençol freático pode-se utilizar a irrigação subterrânea, buscando estudar a garantia de um maior desenvolvimento da planta e um menor estresse hídrico. Já solos com muita umidade implicam na redução do percentual de oxigênio devido dificuldade de aerar, podendo até mesmo gerar morte da planta em longo prazo (KERBAUY, 2004).

Objetivou-se com a pesquisa analisar a influência da profundidade do lençol freático na cultura canola (Brassica napus L.), estudando-se o efeito do fluxo ascendente por capilaridade.

\footnotetext{
${ }^{1}$ CRUCIANI, D.E., A drenagem na agricultura. 4ạ Edição. São Paulo: Nobel, 1987.
} 


\section{MATERIAL E MÉTODOS}

O trabalho foi realizado na sede da Universidade Estadual do Oeste do Paraná - UNIOESTE, localizado na cidade de Cascavel, Paraná, Brasil, latitude 2453'47"S e longitude 5332'09"W, conduzido em casa de vegetação, solo utilizado é classificado como latossolo vermelho distroférrico típico, a temperatura média é de 19ㄷ (EMBRAPA, 2006; IAPAR, 2011).

Utilizaram-se para o atual estudo sementes de canola, pedaços de manta geotêxtil, pratos com diâmetros superiores a $20 \mathrm{~cm}$ e lisímetros confeccionados em policloreto de vinila (PVC) com diâmetros de $20 \mathrm{~cm}$, e comprimentos diferenciados representando as profundidades de lençol freático de 10; 20; 30; 40; 50 e $60 \mathrm{~cm}$ (Figura 1). Onde os lisímetros ficaram assentados sobre bandejas de plástico, separados pela manta geotextil. As bandejas foram mantidas com água para manutenção da umidade como simulador de profundidade do lençol freático,

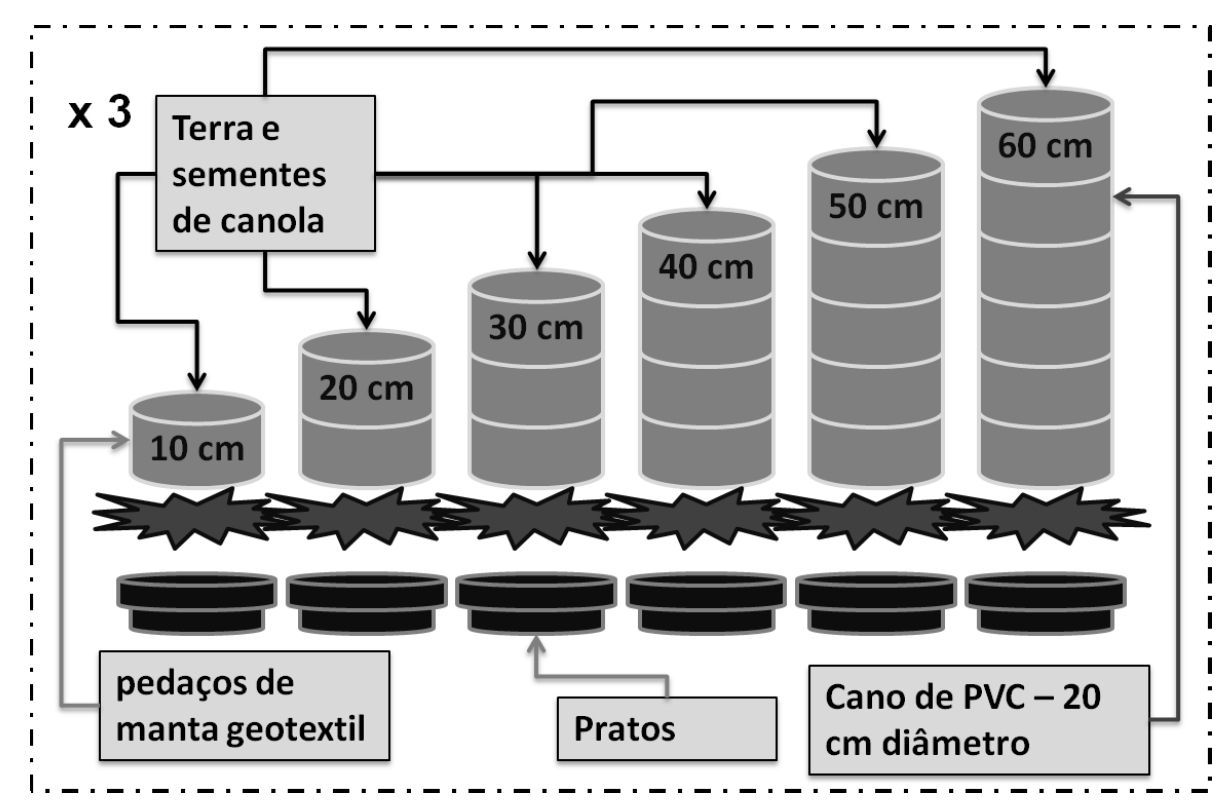

Figura 1. Configuração dos lisímetros confeccionados.

Não houve adição de fertilizantes ou qualquer componente químico. Cultivou-se 2 plantas por lisímetro. O plantio da canola, teve início no dia 10/04/13. Os lisímetros foram irrigados, com aproximadamente $200 \mathrm{~mL}$ de água pela parte superior, apenas durante há primeira semana, com finalidade de garantir germinação. Após esta apenas se adicionava água nas bandejas de plástico na parte inferior dos lisímetros.

As amostras foram retiradas aos 120 dias após semeadura (DAS), sendo as plantas colhidas pela manhã e após pesagem foram tomadas: massa fresca da parte aérea (MFA), e massa fresca da raiz (MFR), onde logo após esses materiais foram colocados em estufa com circulação forçada de ar, à temperatura de $65 \stackrel{\circ}{\circ} \pm 2$ para determinação de massa seca aérea (MSA) e massa seca raiz (MSR). Em seguida as amostras foram pesadas em balança de precisão semi-analítica com precisão de 0,0005 g. Repetiu-se a etapa da estufa com circulação de ar forçada até se atingir peso constante. Analisou-se também, altura de planta (AP) e diâmetro de caule (DC).

As análises estatísticas foram efetuadas seguindo-se o modelo de análise de variância ANOVA - e as médias comparadas pelo teste de Tukey a $5 \%$ de probabilidade de erro, com a 
utilização do pacote estatístico Assistat ${ }^{\circledR}$ versão 7.6 beta. Em função da variação de altura do lençol freático, foram geradas equações de regressão.

\section{RESULTADO E DISCUSSÕES}

Observando-se a Tabela 1, pode-se verificar que todos os parâmetros analisados obtiveram diferenças significativas $(P>0,05)$ do sistema de plantio em profundidades. Através da análise verificou-se em todos os parâmetros analisados correspondem às regressões lineares e superaram com até 99\% de probabilidade, como exposto na Tabela 1.

A profundidade do lençol freático é um dos fatores importantes na área agronômica (MARTINS et al., 2012). No atual experimento ocorreu menor desenvolvimento da planta nos tratamentos: 10 e $20 \mathrm{~cm}$ quanto à análise de MFA; 10, 20 e $30 \mathrm{~cm}$ na MAS; 10 e $20 \mathrm{~cm}$ de diâmetro; e $10 \mathrm{~cm}$ na altura de planta. Sendo coerente com o exposto por Lyra et al. (2003), que relatam proporcionalidade com a elevação do nível do lençol freático e a diminuição na aeração do solo, dificultando o desenvolvimento da planta.

No atual trabalho os melhores resultados foram encontrados nas maiores profundidades do lençol freático sem diferenças significativas $(P<0,05)$ de $30,40,50$ e $60 \mathrm{~cm}$ para MFA e de 40, 50 e $60 \mathrm{~cm}$ MSA. Assim como relatado por Faraji et al. (2009), conseguir MSA é pré-requisito essencial para um alto rendimento de sementes.

Tabela 1. Efeito da variação do nível do lençol freático sobre variáveis. Massa fresca e seca aérea (MFA e MSA), massa fresca e seca da raiz (MFR e MSR), diâmetro do caule (DC) e altura de planta (AP)

\begin{tabular}{ccccccc}
\hline Profundidade do lençol freático & MFA & MAS & MFR & MSR & DC & AP \\
\hline $\mathrm{cm}$ & $\mathrm{g}$ & $\mathrm{g}$ & $\mathrm{g}$ & $\mathrm{g}$ & $\mathrm{g}$ & $\mathrm{g}$ \\
\hline 10 & $5.822 \mathrm{c}$ & $2.949 \mathrm{c}$ & $3.321 \mathrm{c}$ & $1.862 \mathrm{~b}$ & $4.833 \mathrm{~b}$ & $23.167 \mathrm{~b}$ \\
20 & $13.56 \mathrm{bc}$ & $3.047 \mathrm{c}$ & $5.865 \mathrm{bc}$ & $3.380 \mathrm{ab}$ & $6.250 \mathrm{ab}$ & $79.000 \mathrm{a}$ \\
30 & $17.492 \mathrm{ab}$ & $4.802 \mathrm{bc}$ & $6.153 \mathrm{abc}$ & $2.869 \mathrm{ab}$ & $7.166 \mathrm{a}$ & $100.166 \mathrm{a}$ \\
40 & $20.230 \mathrm{ab}$ & $6.238 \mathrm{ab}$ & $9.389 \mathrm{ab}$ & $5.331 \mathrm{ab}$ & $7.666 \mathrm{a}$ & $88.333 \mathrm{a}$ \\
50 & $23.326 \mathrm{a}$ & $5.986 \mathrm{ab}$ & $11.414 \mathrm{a}$ & $6.355 \mathrm{a}$ & $7.500 \mathrm{a}$ & $90.500 \mathrm{a}$ \\
60 & $24.092 \mathrm{a}$ & $7.939 \mathrm{a}$ & $7.738 \mathrm{abc}$ & $4.411 \mathrm{a}$ & $7.000 \mathrm{ab}$ & $87.166 \mathrm{a}$ \\
\hline $\mathrm{RL}$ & $13.827^{* *}$ & $37.572^{* *}$ & $48.987 * *$ & $19.094^{* *}$ & $12.614^{* *}$ & $29.152^{* *}$ \\
$\mathrm{RQ}$ & $2.469 \mathrm{~ns}$ & $0.095 \mathrm{~ns}$ & $3.914 \mathrm{~ns}$ & $5.267 \mathrm{~ns}$ & $8.949 * *$ & $28.6050^{* *}$ \\
\hline MG & 17.420 & 5.060 & 7.313 & 4.035 & 6.736 & 78.055 \\
\hline CV (\%) & 29.63 & 31.53 & 27.19 & 33.29 & 18.46 & 23.80 \\
\hline
\end{tabular}

Médias seguidas da mesma letra não diferem significativamente entre si pelo teste Tukey, ao nível de $5 \%$ de probabilidade. $\left({ }^{* *}\right)=$ significante a $1 \%$ de probabilidade; $\left({ }^{*}\right)=$ significante a $5 \%$ de probabilidade; $\left({ }^{\text {n.s. }}\right)=$ não significante. CV (\%) = coeficiente de variação; R.L. Regressão linear; R.Q. Regressão quadrática.

A profundidade do lençol freático no plantio de canola utilizando-se de latossolo vermelho distroférrico apresentou boa absorção de água por capilaridade através do fluxo ascendente, resultando em melhores resultados de desenvolvimento de planta para maiores profundidades de lençol freático. Segundo Lacerda (2007) esta absorção ocorre devido à camada superficial do solo perder maior quantidade de água, sendo a altura capilar diretamente influenciada pela textura do solo.

A justificativa do pequeno desenvolvimento da canola a $10 \mathrm{~cm}$ de profundidade do lençol freático em todos os parâmetros analisados, pode ser pelo fato de não haver drenagem o 
suficiente, resultando em pouca oxigenação para as raízes, assim como relatado por Tomm et al. (2009), cultivo de canola requer solos drenados e pouco compactados.

Sendo assim o estresse hídrico pode afetar em redução na taxa de germinação e na velocidade desta. Segundo Bewley e Black (1994) pode haver grande variação de respostas entre espécies, desde aquelas muito sensíveis até as mais resistentes, ou seja, a intensidade da resposta germinativa e de crescimento ao estresse hídrico é variável entre sementes de diferentes espécies.

Com este trabalho pode-se notar que o estresse hídrico no cultivo da canola é prejudicial ao seu desenvolvimento no geral. Em condições de baixa disponibilidade de água no solo é de essencial consideração, sendo que podem refletir condições complexas observadas no campo (ÁVILA et al., 2007). Desta forma pode-se indicar condições mínimas e ótimas de potencial hídrico no solo para o desempenho de plântulas, observou-se que a MFA, MSR, diâmetro e altura de planta não apresentaram variações significativamente diferentes de 30 a $60 \mathrm{~cm}$ de profundidade do lençol freático com água.

\section{CONCLUSÃO}

O cultivo da canola em locais onde o lençol freático, de água, é menor que $20 \mathrm{~cm}$ de profundidade tende a gerar dificuldades para seu desenvolvimento, e em profundidades de 40 á 60 são mais indicadas, dentre as testadas, frente a anterior e não apresentam diferenças significativas, entre si, estatisticamente.

\section{REFERÊNCIAS}

1. ÁVILA, M.R. BRACCINI, A.L.; SCAPIM, C.A.; FAGLIARI, J.R.; SANTOS, J.L. Influência do estresse hídrico simulado com manitol na germinação de sementes e crescimento de plântulas de canola. Revista Brasileira de Sementes, v. 29, n.1, p. 98-106, 2007.

2. BAÑUELOS, G. S.; BRYLA, D. R.; COOK, C. G. Vegetative production of kenaf and canola under irrigation in central California. Industrial crops and products, v. 15, p. 237-245, 2002.

3. BEWLEY, J.D.; BLACK, M. Seeds: physiology of development and germination. 2 ed. New York: Plenum Press, 445p, 1994.

4. DOGAN, E.; COPUR, O.; KAHRAMAN, A.; KIRNAK, H.; GULDUR, M. E. Supplemental irrigation effect on canola yield components under semiarid climatic conditions. Agricultural Water Management, v. 98, n. 9, p. 1403-1408, 2011.

5. EMBRAPA- Empresa Brasileira De Pesquisa Agropecuária. Centro Nacional de Pesquisa de Solos. Sistema brasileiro de classificação de solos. Brasília, Embrapa Produção de Informação; Rio de Janeiro, Embrapa Solos, 2006. 312p.

6. FARAJI, A.; LATIFI, N.; SOLTANI, A.; HOSSAIN, A.; RAD, S. Seed yield and water use efficiency of canola (Brassica napus $L$.) as affected by high temperature stress and supplemental irrigation. Agricultural Water Management, v. 96, p. 132-140, 2009.

7. IAPAR-Instituto Agronômico do Paraná. Médias históricas em estações do IAPAR. (2011). Disponível em: http://www.iapar.br/arquivos/Image/monitoramento/Medias_Historicas/Cas cav-el.html. Acesso em: 11/2013. 
8. KERBAUY, G.B. Fisiologia vegetal. Porto Alegre: UFRGS, 2004.

9. LACERDA, C. F. DE. Relações Solo-Água-Planta em Ambientes Naturais e Agrícolas do Nordeste Brasileiro. 2007. Disponível em: http://portais.ufg.br/uploads/68/original_APOSTILA_-_RELA_ _ES_SOLOS_GUA_PLANTA.pdf. Acesso em: 11/2013.

10. LYRA, M.R.C.C.; ROLIM, M.M.; SILVA, J.A.A. Topossequência de solos fertigados com vinhaça: contribuição para a qualidade das águas do lençol freático. Revista Brasileira de Engenharia Agrícola e Ambiental, v.7, p.525-532, 2003.

11. MARTINS, M.F.; CARDOSO, L.P.; SUZUKI, L.E.A.S.; MILANI, I.C.B.; COLLARES, G.L.; DAÍ PRÁ, M. Variação da profundidade do lençol freático em uma área de construção civil em Pelotas-RS. In: 21 ㅇ Congresso de Iniciação Científica - 4a Amostra Cientifica. Universidade Federal de Pelotas, Pelotas-RS, 2012.

12. NIERO R.Z., Acompanhamento do Nível Freático e Determinação da Condutividade Hídrica do Solo na Fazenda Experimental da Ressacada CCA - UFSC, Florianópolis, SC. TCC. Novembro 2011. Disponível em: www.repositorio.ufsc.br . Acesso: 05/2013.

13. RODRIGUES, R.A., "Biodiesel no Brasil: diversificação energética e inclusão social com sustentabilidade". O Futuro da Indústria: Biodiesel, pp.15-26. Série Política Industrial, Tecnológica e de Comércio Exterior, nำ14. Ministério do Desenvolvimento, Indústria e Comércio Exterior, Instituto Euvaldo Lodi, Núcleo Central, 2006.

14. TAPANES, N. D. LA CARIDAD OM; ARANDA, D. A. G.; PEREZ, R. S.; CRUZ, Y. R. Biodiesel No Brasil: Matérias Primas E Tecnologias De Produção. Acta Scientiae e Technicae, v. 1, n. 1, p. 119-125, 2013.

15. TOMM, G.O.; RAPOSO, R.W.C.; SOUZA, T. A. F.; OLIVEIRA, J. T.; L. RAPOSO, E. H. S.; SILVA NETO, C. P.; BRITO, A. C.; NASCIMENTO, R. de S.; RAPOSO, A. W. S. SOUZA, C. F. Desempenho de genótipos de canola (Brassica napus L.) no Nordeste do estado da Paraíba, Nordeste do Brasil. Boletim de Pesquisa e Desenvolvimento on-line, Ministério da Agricultura, Pecuária e Abastecimento. Passo Fundo, RS. 2008.

16. TOMM, G.O.; WIETHÖLTER, S.; DALMAGO, G.A.; SANTOS, H.P. Tecnologia de produção de canola no Rio Grande do Sul. Passo Fundo: Embrapa Trigo, 2009. ISSN 1518-6512. Documentos Online, 113. Disponível em: http://www.cnpt.embrapa.br/biblio/do/p_do113.pdf . Acesso em: $11 / 2013$. 